\title{
The impact of natural resource rent, financial development, and urbanization on carbon emission
}

\author{
Shi-Zheng Huang ${ }^{1} \cdot$ Muhammad Sadiq $^{2} \cdot$ Fengsheng Chien ${ }^{3,4}$
}

Received: 31 July 2021 / Accepted: 26 September 2021 / Published online: 15 October 2021

(c) The Author(s), under exclusive licence to Springer-Verlag GmbH Germany, part of Springer Nature 2021

\begin{abstract}
There is a shred of evidence of environmental degradation in the form of carbon emissions to behave differently when tested with different macroeconomic variables. This paper aims to examine the long-run and short-run association between natural resource rent, financial development, and urbanization on carbon emission from the context of the USA during 1995-2015 with the help of a contemporary and innovative approach named quantile autoregressive distributed lagged model (QARDL). The stated approach is applied due to the fact that non-linearity is observed for the study variables. The findings indicated that the higher financial development (0.304), natural resource rent (0.102), and urbanization (0.489) have a positive impact on the environmental degradation in the region of USA during long-run estimation in the stated quantiles of the study. This would indicate that higher financial development, urbanization, and natural resources are putting more environmental pressure on the economy of the USA. Similarly, the findings under short-run estimation confirm that past and lagged values of carbon emission, financial development, natural resource rent, and urbanization are significantly determining the current values of the carbon emission. For this reason, it is suggested that the government requires some immediate steps of the USA to control the harmful effect of such financial development, more urbanization, and higher natural resource rent as well. This would indicate the reflection of some green strategies in all three explanatory variables to generate some fruitful environmental outcomes.
\end{abstract}

Keywords Natural resource rent · Financial development · Urbanization · Carbon emission

\section{Introduction}

Responsible Editor: Roula Inglesi-Lotz

Fengsheng Chien

jianfengsheng@fzfu.edu.cn

Shi-Zheng Huang

szhuang06@gmail.com

Muhammad Sadiq

muhammad.sadiq@taylors.edu.my

1 School of Economics and Management, Guangdong University of Petrochemical Technology (GUTP), Maoming 525000, China

2 School of Accounting and Finance, Faculty of Business and Law, Taylor's University Malaysia, Subang Jaya, Malaysia

3 School of Finance and Accounting, Fuzhou University of International Studies and Trade, Fuzhou, China

4 Faculty of Business, City University of Macau, Macau, China
Over the time span of recent and the past decades, one of the significant environmental turmoil is global warming, which has reshaped the climate change in the world economy (Amen et al. 2021; Chien et al. 2021a; Mohsin et al. 2021; Umar et al. 2020). Meanwhile, with the growing number of human activities, labor, and production of goods and services, there is a mounting trend in terms of the economy at a world glance (Bekun et al. 2019; An et al. 2021a, b; Wu et al. 2021; Wang et al. 2021a, b). At the same time, competition in terms of natural resources and sustainability is also linked with the ED. In this regard, carbon dioxide emission (CO2EM) is considered the largest contributor to environmental issues like degradation (Shan et al. 2021; An et al. 2021a; Umar et al. 2021a, b). It has been found that over the last 130 years, the concentration of CO2EM in the natural environment has been increased about 45 (Bekun et al. 2019; Hu et al. 2021; Tsunga et al. 2020). In addition to the carbon emission from plants, animals, and various 
other sources, different energy sources also play a major role in creating more emissions in the natural environment. Another growing concern is that anthropogenic CO2EM traps heat in the atmosphere, hence causing a big increase in the global temperature (Aymerich and Herce 2020; Mignamissi and Djeufack 2021; Razzaq et al. 2021a, b, c, d; He et al. 2018). For this reason, $\mathrm{CO} 2$ emission remains among the focal factors towards environmental sustainability and changing climate issues. In this regard, the mitigation of carbon dioxide in the natural environment has become the priority specifically for the advanced economies of the world (Razzaq et al. 2020; Chen et al. 2018).

In addition, as per the findings of the British Petroleum statistical review of the world energy, it is found that CO2EM has been increased from 29,714.2 to 33,444.0 million tons during the period of 2009 to 2017. Turning towards the economy of the USA, the per capita $\mathrm{CO} 2$ emission has also been increased from 0.04 to 16.16 tons during the period of 1800 to 2017. At the same time, the annual CO2EMs in the region of the USA have also been increased from 267,472 tons to 5.28 billion tons by 2019 . Figure 1 provides a graphical outlook for the $\mathrm{CO} 2$ emission by fuel types in the USA, where the major portion comes from oil, coal, and gas, respectively.

In determining the level of carbon emission and environmental sustainability, the role of natural resource rent (NRR) is not something that can be neglectable. Those economies that are blessed with natural resources ought to be better off and get quicker development than those without valuable natural resources and capital (Huang et al. 2020; Ncube and Koloba 2020; Umar et al. 2020). However, it is also argued that some countries with abundant natural resources have experienced a high level of inequality in income, poverty, and civil issues than others less well-endowed. In this regard, the question of the influence of natural resource abundance on economic growth has got much attention from researchers and policymakers. However, as found in the existing literature, one of the key issues is that very little consensus has been conducted on whether the NRR has a significant positive or negative influence on environmental sustainability in the form of carbon emissions. This is due to the fact that much work is conducted on the association between natural resources and economic growth, which can be traced back to the seventeenth century (Kennedy et al. 2020; Odugbesan and Rjoub 2020; He et al. 2018; Zhao et al. 2021a, b).

In addition, it is accepted that urban areas have become one of the main sources of higher carbon emissions (Lawrence 2020; Li et al. 2021a, b, c, d, e, f; Wang et al. 2021a, b). For this reason, the impact and influence of urbanization on carbon emission have attracted widespread attention for a longer period of time. (Wang et al. 2021a, b; Zhuang et al. 2021; Chen et al. 2018). Due to the burning of fossil fuels, urban areas account for more than $70 \%$ of the carbon emission. In the case of the USA, the degree of urbanization has dramatically been increased from 73.6 to $82.46 \%$ during the period of 1970 to 2019. In this regard, a higher level of URB leads to more problems in the form of climate change and carbon emission. The core motivation to conduct this study is to examine the role of financial development (FD), urbanization, and NRR in determining the level of carbon emission for the economy of the USA, which is under little observation in the past literature. In this regard, the review of the empirical literature has provided a good justification for the role of targeted explanatory variables in determining the changing climate like $\mathrm{CO} 2$, for which the US economy is entirely neglected. This means that although the USA is experienced with the increasing threat from the changing climate, a little policy implication and theoretical and
Fig. $1 \mathrm{CO}_{2}$ emissions by fuel type, USA. Source: Global Carbon Project

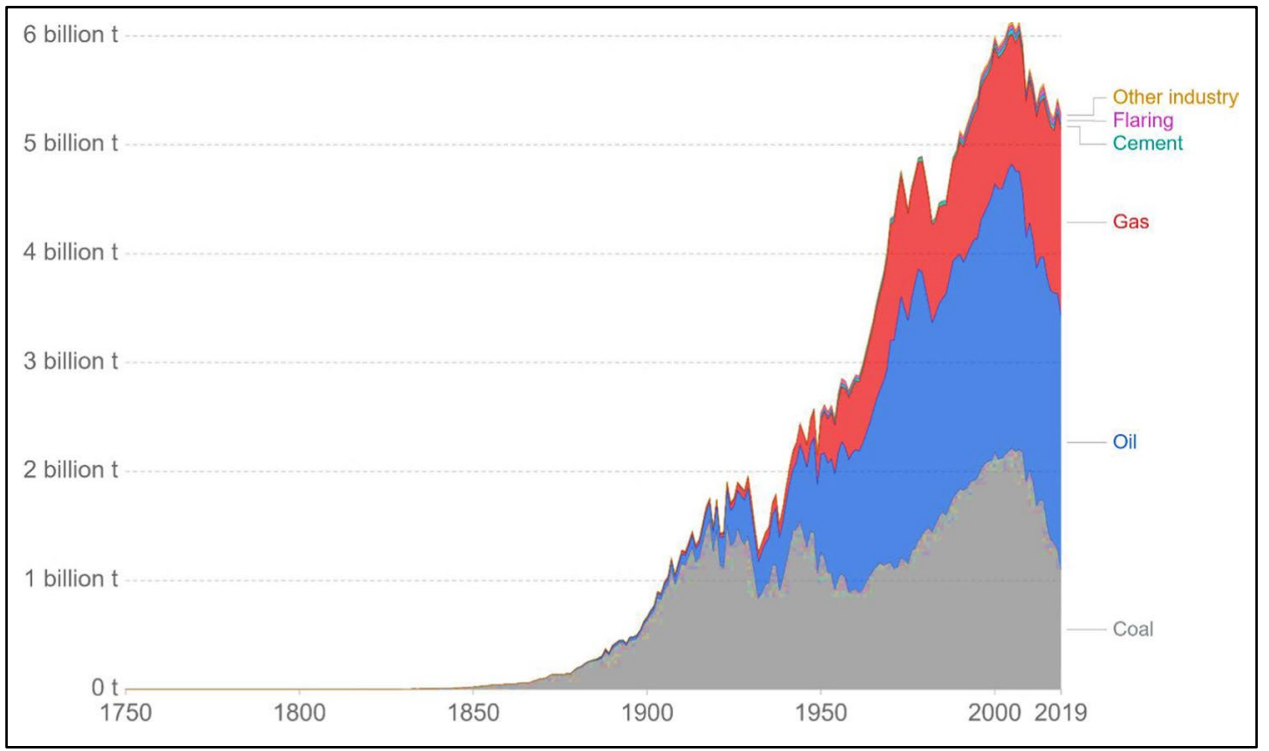


empirical justification are entirely skipped by the researchers. This would provide a great motivation to conduct this research with the help of an innovative approach named QARDL because QARDL has various advantages, such as it allows investigating the relationships among constructs in long-term and short-run dynamics throughout "a span of quantiles of the conditional distribution" of understudy constructs (Mensi et al. 2019). In addition, it also allows for locational asymmetry among the constructs according to the location of the understudy constructs within its conditional distribution (Lahiani 2018). Finally, QARDL lets the cointegrating coefficients to modification over the innovation quantile originated from shocks (Hsu et al. 2021; Shahbaz et al. 2018). Additionally, the causal association between the study variables is checked with the help of the Granger causality technique while considering all three ranges of lower, medium, and higher-order quantiles (Ehsanullah et al. 2021; He et al. 2021; Umar et al. 2021a, b).

In the selected economies of the USA, the environmental quality is being adversely affected by the increase in the amount of $\mathrm{CO} 2$ emission into the air, and thus, it has a negative impact on economic growth. In such a situation, especially during COVID-19, the government, economists, corporate authorities, and policymakers need to be aware of how they can overcome the amount of $\mathrm{CO} 2$ emission into the atmosphere (Lin and Raza 2020). This issue attracts the attention of researchers and academics. That is why our study aims to explore the factors which have a significant influence on $\mathrm{CO} 2$ emission and environmental degradation, and with the proper management of these factors, the amount of $\mathrm{CO} 2$ can be controlled. The study's objective is to explore the impacts of natural resource rent (NRR), financial development (FD), and urbanization on $\mathrm{CO} 2$ emission into the air. This is a gap study as in the past literature, and one can hardly find a study that collectively deals with the influences of NRR, FD, and urbanization on $\mathrm{CO} 2$ emission.

The rest of the paper is organized as follows. A literature review for the study variables is provided under the "Literature review" section. Research methods and descriptions of the study variables are provided under the "Research methods" section, whereas results and discussion are provided in the "Results and discussion" section. Lastly, the conclusion and policy implications are shown in the "Conclusion" section.

\section{Literature review}

\section{Natural resource rent and carbon emission}

The linkage between NRR and carbon emission is widely investigated in both developed and emerging economies
(Chien et al. 2021b; Chien et al. 2021g; Li et al. 2021a, $\mathrm{b}, \mathrm{c}, \mathrm{d}, \mathrm{e}, \mathrm{f})$. In this regard, one of the recent contributions is Bekun et al. (2019), who observe the sustainable environment trends while considering the nexus between resource rent, carbon emission, and other explanatory variables in $16 \mathrm{EU}$ economies during the period of 1996-2014. For the data analysis, the panel pooled mean group-autoregressive distributed lagged model was applied. The study findings observe the positive association between countries' NRR and carbon emission under longrun estimation. Ullah et al. (2021a) examine the nonlinear association between NRR and ecological footprint for the top 15 renewable energy economies. Data were collected during the period of 1996-2018 for implementing the panel smooth transition model. The result shows that there is a significant and positive association between NRR and ecological footprints in both high and low-income regimes. Tufail et al. (2021) have provided their empirical insight while examining the role of natural resources and fiscal decentralization in dealing with the carbon emission for the OECD economies during 1990-2018. However, the study findings reveal that natural resource rent improves the natural environment by reducing carbon emissions. Joshua and Bekun (2020a) conducted an empirical investigation to analyze the role of energy consumption and the NRR in determining carbon emissions in South Africa. The study findings show that there exists a long-run association between pollutant emission and total NRR in the economy of South Africa. Wang et al. (2020) have examined the role of NRR along with other macroeconomic variables in dealing with carbon emissions for the G7 economies. The study findings reveal that NRR is causing more carbon emissions in G7 countries. Anh Tu et al. (2021) conducted a panel investigation during 1995-2017 for the economy of China. The findings indicate that national NRR is positively linked with carbon emission in China. Huang et al. (2021) have considered the role of energy consumption and NRR in determining the carbon emission of China during the period of 1995-2019 while testing for the EKC. The study findings confirm that NRR has some substantial implications for the environmental quality of the Chinese economy. Besides, there are some other studies that have tested for the association between NRR and environmental issues like carbon emission (Canh et al. 2020; Chien et al. 2021c; Joshua and Bekun 2020b; Li et al. 2021a, b, c, d, e, f; Ulucak and Ozcan 2020). Based on the above literature, it is inferred that although the linkage between natural resources and ED-like carbon emission is investigated by the researcher, yet their regional context needs to explore specifically from the context of the USA. A literary workout was done by Bekun et al. (2019) to investigate the longrun causal interaction between natural resource rent, $\mathrm{CO} 2$ emission, and environmental degradation. The empirical 
evidence for this study is based on panel data for the period of 1996-2114 for particular 16 EU countries. Data were analyzed with the help of the panel pooled mean groupautoregressive autoregressive distributive lag model (PMG-ARDL). This study analyzes the impacts of energy resources on the $\mathrm{CO} 2$ emission, and the results elaborate that if proper management or conservation methods are not applied, the natural resource rent enhances the $\mathrm{CO} 2$ emission into the air. Empirical research was made by Ullah et al. (2021b), to identify the interrelationship between renewable energy consumption, natural resource rent, $\mathrm{CO} 2$ emission, and environment quality in the context of the world's top 15 renewable energy consumption economies to attain sustainable development. The study utilizes panel time-series data for the period of 1996-2018. Panel smooth transition model is utilized to explore the relationship and transition between the low and high regimes. This study concludes that natural resource rent causes an increase in the amount of $\mathrm{CO} 2$ into the air and leads to environmental degradation. Recently Razzaq et al. (2021c) also explored the resources depletion effect attributed to infrastructure development in highly resource consuming economies and argued that innovation can help to reduce these negative effects. Similar results are echoed by recent literature using OECD, China, and BRICS sample, respectively (Razzaq et al. 2021a, b).

\section{Financial development and carbon emission}

The association between FD and $\mathrm{CO} 2$ emission is also investigated both in theoretical and empirical perspectives but observe with some mixed findings (Chien et al. 2021d; Nawaz et al. 2021a, b; Shair et al. 2021). For example, Ozturk and Acaravci (2013) have considered the economy of Turkey for exploring the dynamic association between FD, energy consumption, and carbon emission during 1960-2007. However, their study findings indicate that under the theoretical assumption of EKC, there is no significant impact of FD on per capita carbon emission under long-run estimation. Another study conducted by Odugbesan and Adebayo (2020) has tested the symmetric and asymmetric effect of FD on the carbon emission for the economy of Nigeria during 1981-2016 with the help of linear ARDL and nonlinear ARDL estimation. The study findings confirm that there is a positive and long-run association between FD and carbon emission in the Nigerian economy. Guo and $\mathrm{Hu}$ (2020) cover the Chinese economy for checking the short-run as well as the long-run effect of FD on carbon emission during 1997-2016. The study findings through the autoregressive distributed model confirm a weak carbon emission reduction effect of FD both in the long run and short run. However, the absolute value for the coefficient of FD on carbon emission in the long run is greater than in the short run. $\mathrm{Lv}$ and $\mathrm{Li}$ (2021) have tested the presence of EKC with the help of FD, globalization, and carbon emission for the BRICS countries through a range of statistical tests. The study findings confirm that there is a cross-sectional dependence between FD and carbon emission, whereas FD significantly contributes towards carbon emission, which supports the presence of EKC.

Ali et al. (2019) examined the dynamic effect of FD on carbon emission during 1971-2010 with the help of autoregressive and bound testing approaches. The study results show that carbon emission is positively and significantly affected by FD under long-run estimation. Koondhar et al. (2021) have revisited the association between agriculture FD, energy consumption, and carbon emission for the economy of China during 1998-2018 while taking into account both short-run and long-run observation. The study findings indicate that carbon emission is showing an upward direction with the increase in the agriculture FD of China. For the role of FD in dealing with the environmental issues, most of the research work is carried out in different economies whereas a little investigation is conducted for the economy of USA while suggesting some sustainable solutions. Therefore, this study has considered the role of FD and other explanatory variables to suggest some diverse policy parameters. The intellectual like Zaidi et al. (2019) observe the association between financial development, globalization, and $\mathrm{CO} 2$ emissions in Asia Pacific Economic Cooperation (APEC) countries in case of economic growth and energy intensity under the model of environment Kuznets curve (EKC). For analysis, panel data for the period 1990-2016 and Westerlund co-integration techniques are applied. Moreover, CUP-BC and CUP-FM methods are applied to check the relationship between the variables. The study results indicate that though the financial development in the form of an increase in the financial resources is helpful to reduce $\mathrm{CO} 2$ emission, in case financial development brings an increment in the economic growth and energy consumption, it causes an increase in the $\mathrm{CO} 2$ emission. An observation was made by Charfeddine and Kahia (2019) to integrate a relationship between financial development, renewable energy consumption, $\mathrm{CO} 2$ emission, and economic growth and employs the panel vector autoregressive (PVAR) model for analysis. The analysis about the nature of association between these variables was made for 24 countries in the Middle East and North Africa (MENA) regions for 1980-2015. The study implies that if the financial development encourages renewable energy consumption within the economy, it reduces the $\mathrm{CO} 2$ emission into the air.

\section{Urbanization and carbon emission}

It is observed that urbanization has played a major role in determining the ED in recent and past years (Chien et al. 2021e; Sun et al. 2020). In this regard, Prastiyo and 
Hardyastuti (2020) have conducted their empirical investigation for the role of urbanization along with agriculture and manufacture in shaping the level of carbon emission, specifically in the Indonesian economy. The study findings have confirmed the presence of EKC while claiming that urbanization and other explanatory variables are affecting the escalation of GHG emissions in Indonesia. Zhang et al. (2020) examined the cross-country analysis for the effect of urbanization on CO2EM. For this purpose, data were collected from 141 countries during the period of 1961-2011 under the theoretical assumption of the extended STRPAT framework. The study findings show that there is an inverted U-shaped association between urbanization and carbon emission. Wang and Wang (2021) specify that population and carbon emission have risen as two of the major challenges for the sustainable development of society. For this reason, their study has examined the effect of population aging on carbon emission by creating a panel threshold regression model during the period of 2002-2012 for 137 economies. It is found that with the increasing level of population aging, there is a positive correlation between industrial infrastructure and carbon emission (Zhao et al. 2021a, b).

Zhou et al. (2019) have explored the impact of urbanization on carbon emissions in China. The key contribution of their study was to consider various sub-system mechanisms of urbanization to investigate the trends in carbon emissions. The study findings confirm that under different sub-systems of urbanization, the level of CO2EM changes with the passage of time. Hanif (2018) tests the effect of urbanization on the carbon emission of Sub-Saharan African countries during the period of 1995-2015 with the help of a generalized method of moment (GMM) approach. The study findings show that the expansion of urban areas significantly contributes to the carbon emission in the targeted economies. Musah et al. (2021) have examined the linkage between carbon emission and urbanization for the West of Africa with the help of a range of statistical approaches. The study found a significant and positive impact of urbanization on $\mathrm{CO} 2$ emission in all the panel economies. Dong et al. (2021) focus on urbanization and industrialization in order to check their role in environmental protection and economic growth. Data were collected from 2002 through 2017, and panel estimation was applied. The study findings confirm that carbon emission is adversely associated with urban health as a $1 \%$ increase in the value of $\mathrm{CO} 2$ emission may lead to $0.162 \%$ inpatients in the economy of China. Chien et al. (2021f) and Huo et al. (2021) consider the building sector in determining the linkage between carbon emission and urbanization. The study findings confirm that the rural residential building sector will be the first to reach the emission and energy peak in China. Although the researchers reasonably provide the literature support for the linkage between urbanization and carbon emission, their regional verification, specifically from the context of the USA, is yet to cover. This would indicate a theoretical as well as a regional gap, which is reasonably covered under the present study analysis. Zhang et al. (2018), have conducted an empirical investigation in order to identify the relationship between urbanization and $\mathrm{CO} 2$ emission. The study extracts panel data from 2005-2014 and employs stochastic impacts by regression on population, affluence, and technology (STIRPAT) model to examine the impacts of urbanization on $\mathrm{CO} 2$ under the alteration of central gravity. The study examines different dimensions of urbanization like land and population urbanization. Its results indicate that urbanization causes an increase in the amount of $\mathrm{CO} 2$ emission within the country. A research analysis was made by Mahmood et al. (2020), to analyze the impacts of rapid growth of urbanization on $\mathrm{CO} 2$ emission under the influence of industrialization. In order to infer the results about the association between urbanization and $\mathrm{CO} 2$, the study analyzes urbanization and industrialization in Saudi Arabia using annual data from 1968 to 2014. The study results confirm a significant positive impact of urbanization under the influence of industrialization on $\mathrm{CO} 2$ emission. It states that urbanization enhances the industrial activities like the use of non-renewable energy resources (the combustion of fossil fuels) which cause the large amount of $\mathrm{CO} 2$ emission.

\section{Research methods}

Under the present study, it has been determined to examine the nonlinear association between the carbon emission, FD, NRR, and urbanization in the economy of the USA during the period of 1995-2015. For this purpose, the quantile autoregressive distributed lagged (QARDL) approach, which is suggested by Cho et al. (2015), has been applied here. Various benefits have been observed for applying the QARDL in sustainability, energy economics, and carbon emission literature. For example, QARDL helps to predict the impact of a set of explanatory variables on the dependent variable with the help of a low, medium, and higher-order quantiles (Jiang et al. 2021; Liu et al. 2021; Nawaz et al., 2021a, b; Shan et al. 2021). Moreover, QARDL has various advantages, such as it allows investigating the relationships among constructs in long-term and short-run dynamics throughout "a span of quantiles of the conditional distribution" of understudy constructs (Mensi et al. 2019; Othman et al. 2020; Sadiq et al. 2021b). In addition, it also allows for locational asymmetry among the constructs according to the location of the understudy constructs within its conditional distribution (Lahiani 2018; Sadiq et al. 2021a; Xueying et al. 2021). Finally, QARDL lets the cointegrating coefficients to modification 
over the innovation quantile originated from shocks (Shahbaz et al. 2018). Furthermore, the dependability of the regression parameters as measured under each of the quantiles has been checked through the Wald test for both longrun and short-run equilibrium. However, the traditional model linear ARDL specification is presented as follows:

$$
\begin{aligned}
\mathrm{CO}_{t} t & =\alpha+\sum_{i}^{p} \beta_{1} \mathrm{CO}_{\text {sit-in }}+\sum_{i}^{q} \beta_{2} \mathrm{NPR}_{\text {sit-in }} \\
& +\sum_{i}^{m} \beta_{3} \mathrm{FD}_{\text {sit-in }}+\sum_{i}^{n} \beta_{4} \mathrm{URB}_{\text {sit-in }}+\epsilon_{t}
\end{aligned}
$$

In the above equation, the notion like $\mathrm{CO} 2, \mathrm{NRR}, \mathrm{FD}$, and URB shows the titles for CO2EMs, NRR, FD, and urbanization, respectively. Additionally, $\epsilon_{t}$ reflects the white noise error term as explained by the lowest field created through $\mathrm{CO} 2$, NRR, FD, and URB, respectively. Meanwhile, the titles like $p, q, m$, and $n$ are showing the lag orders as observed through Schwarz info criterion (SIC). Besides, all the study variables are measured by taking the natural log of their relative values as collected from the world development indicator (WDI) during the study period. However, the revision of Eq. 1 into the context of quantile regression can provide the following Eq. 2 .

$$
\begin{aligned}
Q_{\mathrm{CO}_{t} t} & =\alpha(\tau)+\sum_{i}^{p} \beta_{1}(\tau) \mathrm{CO}_{\text {sit-in }}+\sum_{i}^{q} \beta_{2}(\tau) \mathrm{NPR}_{\text {sit-in }} \\
& +\sum_{i}^{m} \beta_{3}(\tau) \mathrm{FD}_{\text {sit-in }}+\sum_{i}^{n} \beta_{4}(\tau) \mathrm{URB}_{\text {sit-in }}+\epsilon_{t}(\tau)
\end{aligned}
$$

In order to go for the data analysis, the pair of quantiles ranging from 0.05 th to 0.95 th, respectively, has been utilized here. Additionally, due to the probability of sequential association in the white noise error, the QARDL framework as shown in Eq. 2 is expressed by following Eq. 3 of the study.

$$
\begin{aligned}
Q_{\Delta \mathrm{CO}_{t}} & =\alpha(\tau)+\rho \mathrm{CO}_{\text {sit-in }}+\varphi_{1} \mathrm{NPR}_{t-i}+\varphi_{2} \mathrm{FD}_{t-i}+\varphi_{3} \mathrm{URB}_{t-i} \\
& +\sum_{i}^{p} \beta_{1}(\tau) \mathrm{CO}_{t-i}+\sum_{i}^{q} \beta_{2}(\tau) \mathrm{NRR}_{t-i}+\sum_{i}^{m} \beta_{3}(\tau) \mathrm{FD}_{t-i} \\
& +\sum_{i}^{n} \beta_{4}(\tau) \mathrm{URB}_{t-i}+\epsilon_{t}(\tau)
\end{aligned}
$$

The above Eq. 3 can be revised into Eq. 4 as per the suggestion of Cho et al. (2015) to consider the error correction estimation for the QARDL framework.

$$
\begin{aligned}
Q_{\Delta \mathrm{CO}_{t}} & =\alpha(\tau)+\rho(\tau)\left(\mathrm{CO}_{t-i}-\omega_{1}(\tau) \mathrm{NRR}_{t-i}-\omega_{2}(\tau) \mathrm{FD}_{t-i}-\omega_{3}(\tau) \mathrm{URB}_{t-i}\right) \\
& +\sum_{i=1}^{p-1} \beta_{1}(\tau) \Delta \mathrm{CO}_{t-i}+\sum_{i=0}^{q-1} \beta_{2}(\tau) \Delta \mathrm{NRR}_{t-i}+\sum_{i=0}^{m-1} \beta_{3}(\tau) \Delta \mathrm{FD}_{t-1} \\
& +\sum_{i=0}^{n-1} \beta_{4}(\tau) \Delta \mathrm{URB}_{t-i}+\epsilon_{t}(\tau)
\end{aligned}
$$

Considering the delta technique, the collective shortterm impact of past carbon emission on the current $\mathrm{CO} 2$ is measured through $\beta_{*}=\sum_{i=1}^{p-1} \beta_{1}$. Furthermore, the remaining short-term impact of the past and current FD, NRR, and urbanization on the current level of carbon emission is also examined with the help of a similar approach. Finally, it is assumed that the speed of adjustment coefficient or $p$ in the Eq. 4 will be observed as significant and negative.

After conducting QARDL estimation, the next step is to analyze the study variables with the help of Granger causality in the quantiles. For this purpose, the Granger causality test assumes that the current value of the carbon emission (main dependent variable) is determined with the help of its current values as well as lagged scores of all the explanatory variables of the study. This research has utilized a recent approach for investigating the Granger causality between the study variables with the help of quantile causal estimation suggested by Troster.

\section{Results and discussion}

Table 1 shows the output for the descriptive statistics covering mean, minimum, maximum, and standard deviation, respectively. It is observed that FD has a higher mean and maximum trend comparatively to the rest of the variables. Similarly, the mean score for CO2EM is higher than NRR and urbanization as well. It means that the economy of the USA is facing a higher level of FD in terms of log scores compared to carbon emission, NRR, carbon emission, and urbanization as well. The J-B test is applied to examine the normality trends where the null hypothesis assumes that data is usually distributed, whereas the alternative indicates that it is not. The findings indicate that scores for J-B for all the study variables are significant at $1 \%$, confirming the non-normal distribution of the study variable. This would justify the implication of a quantile autoregressive distributed lagged model.

The findings for the unit root test are shown in Table 2 of the study. For this purpose, ADF and ZA tests are under consideration. The findings indicate that ADF (level) has shown insignificant output for all the study variables like carbon emission, NRR, FD, and urbanization. However, the scores for $\operatorname{ADF}(\Delta)$ are showing highly significant outcomes at $1 \%$. Similarly, the values for ZA at the level are not significant, whereas ZA $(\Delta)$ is found to be negatively significant. This would justify the argument that all the study variables are

Table 1 Results of descriptive statistics

\begin{tabular}{llllll}
\hline Variables & Mean & Min & Max & Std. dev & J-B stats \\
\hline $\mathrm{CO}_{2}$ & 1.573 & 1.010 & 2.011 & 0.004 & $20.001 * * *$ \\
$\mathrm{NRR}$ & 0.739 & 0.079 & 1.010 & 1.807 & $17.107 * * *$ \\
$\mathrm{FD}$ & 2.010 & 1.564 & 3.003 & 0.054 & $22.102 * * *$ \\
$\mathrm{URB}$ & 0.951 & 0.059 & 1.015 & 1.064 & $19.010^{* * *}$ \\
\hline
\end{tabular}

Note: The *** represents level of significance at $1 \%$ 
stationarity at a $5 \%$ significance level under $\operatorname{ADF}(\Delta)$ and $\mathrm{ZA}(\Delta)$, respectively.

In addition, the findings for the QARDL estimation have been presented in Table 3 of the study. It is observed that different quantiles ranging from lower to higher-order are reported along with error correction parameters, long-run coefficients, short-run coefficients, and their standard error are also shown under a similar table. The findings for the QARDL estimation show that the value of the error correction model of $p^{*}$ is significant and negative for different study quantiles. This would justify a presence of valid reversion to long-run asymmetry association between carbon dioxide emission, and FD, NRR, and FD. Furthermore, the findings in Table 3 confirm that there is a significant and positive association between the NRR and CO2EM. More specifically, the impact of NRR on CO2EM is highly significant at higher-order quantiles and only significant at lowerorder quantiles. However, this impact is maximum for the 0.80th quantile with the coefficient of 0.151 at a $1 \%$ level of significance. A range of studies have been found in existing literature covering the dynamic association between NRR and carbon emission in different economies. For instance, Bekun et al. (2019) $16 \mathrm{EU}$ member states to investigated the trends in a sustainable environment using $16 \mathrm{EU}$ member countries and found a positive association between NRR and carbon emission in the long run. This would justify the argument that overdependence on NRR is significantly impacting environmental sustainability. Wang et al. (2020) have considered G7 economies to investigate the association between NRR, carbon emission, and other explanatory variables. It

Table 2 Results of unit root test

\begin{tabular}{lllllll}
\hline Variables & ADF $($ level $)$ & ADF $(\Delta)$ & ZA (level) & Break year & ZA $(\Delta)$ & Break year \\
\hline $\mathrm{CO}_{2}$ & -1.105 & $-3.024^{* * *}$ & -1.110 & $2004 \mathrm{Q} 1$ & $-6.010^{* * *}$ & 2009 Q2 \\
$\mathrm{NRR}$ & -0.010 & $-5.010^{* * * *}$ & -0.020 & $2012 \mathrm{Q} 2$ & $-8.011^{* * *}$ & $2016 \mathrm{Q} 1$ \\
$\mathrm{FD}$ & 1.123 & $-4.401^{* * *}$ & 1.132 & $2015 \mathrm{Q} 1$ & $-9.011^{* * *}$ & $2009 \mathrm{Q} 1$ \\
$\mathrm{URB}$ & -0.301 & $-6.007 * * *$ & -0.401 & $2008 \mathrm{Q} 4$ & $-7.101^{* * *}$ & 2015 Q4 \\
\hline
\end{tabular}

Source: Author estimation. Note: The *** represents level of significance at $1 \%$

Table 3 Results of quantile autoregressive distributed lag (QARDL) for $\mathrm{CO}_{2}$ emission

\begin{tabular}{|c|c|c|c|c|c|c|c|c|c|c|}
\hline \multirow{2}{*}{$\begin{array}{l}\text { Quantiles } \\
(\tau)\end{array}$} & \multirow{2}{*}{$\begin{array}{l}\text { Constant } \\
\alpha_{*}(\tau)\end{array}$} & \multirow{2}{*}{$\begin{array}{l}\text { ECM } \\
\rho_{*}(\tau)\end{array}$} & \multicolumn{3}{|c|}{ Long-run estimation } & \multicolumn{5}{|c|}{ Short-run estimation } \\
\hline & & & $\beta_{\mathrm{NRR}}(\tau)$ & $\beta_{\mathrm{FD}}(\tau)$ & $\beta_{\mathrm{URB}}(\tau)$ & $\varphi_{1}(\tau)$ & $\omega_{0}(\tau)$ & $\lambda_{0}(\tau)$ & $\theta_{0}(\tau)$ & $\theta_{1}(\tau)$ \\
\hline \multirow[t]{2}{*}{0.05} & 0.011 & -0.215 & $0.102 *$ & $0.304 * *$ & $0.489 * * *$ & $0.380 * *$ & $0.121^{*}$ & $0.020 * *$ & $0.022 * *$ & 0.057 \\
\hline & $(0.010)$ & $(-0.010)$ & (1.963) & (2.110) & (2.991) & $(2.265)$ & (1.687) & $(2.795)$ & $(2.221)$ & $(0.095)$ \\
\hline \multirow[t]{2}{*}{0.10} & 0.012 & -0.241 & $0.126^{*}$ & $0.310 * *$ & $0.468 * * *$ & $0.369 * *$ & $0.129 * *$ & $0.091 * *$ & $0.023 * *$ & 0.048 \\
\hline & $(0.001)$ & $(-0.006)$ & (1.958) & (1.991) & (3.000) & $(1.971)$ & $(2.001)$ & $(2.691)$ & $(2.312)$ & $(0.081)$ \\
\hline \multirow[t]{2}{*}{0.20} & 0.008 & $-0.257 *$ & $0.132 *$ & $0.319 *$ & $0.477 * * *$ & $0.372 * *$ & $0.133 * *$ & $0.081 * *$ & $0.019 *$ & 0.040 \\
\hline & $(0.010)$ & $(-1.954)$ & (1.936) & $(1.716)$ & (3.192) & (1.980) & $(2.210)$ & (1.982) & (1.910) & $(0.075)$ \\
\hline \multirow[t]{2}{*}{0.30} & 0.017 & $-0.248^{*}$ & $0.120 *$ & 0.308 & $0.462 * *$ & $0.357^{*}$ & 0.142 & 0.072 & $0.026^{*}$ & 0.051 \\
\hline & $(0.003)$ & $(-1.964)$ & (1.947) & $(1.530)$ & $(2.755)$ & (1.959) & (1.600) & $(0.991)$ & (1.714) & $(0.086)$ \\
\hline \multirow[t]{2}{*}{0.40} & 0.061 & $-0.259 * *$ & $0.131 * *$ & 0.312 & $0.470 * *$ & $0.369^{*}$ & 0.136 & 0.088 & 0.040 & 0.031 \\
\hline & $(0.103)$ & $(-1.980)$ & (2.777) & (1.087) & (1.967) & (1.899) & (1.158) & (1.559) & $(0.820)$ & $(0.080)$ \\
\hline \multirow[t]{2}{*}{0.50} & 0.110 & $-0.249 * *$ & $0.124 * *$ & 0.313 & $0.458^{*}$ & $0.359 *$ & 0.139 & 0.071 & 0.033 & 0.043 \\
\hline & $(0.011)$ & $(-1.990)$ & $(2.550)$ & (1.105) & (1.948) & (1.880) & $(0.998)$ & (0.989) & $(0.922)$ & $(0.098)$ \\
\hline \multirow[t]{2}{*}{0.60} & 0.109 & $-0.260 * *$ & $0.134 * *$ & 0.341 & $0.466^{*}$ & $0.348 *$ & 0.143 & 0.059 & 0.059 & 0.052 \\
\hline & $(0.021)$ & $(-2.011)$ & (2.637) & (1.111) & (1.939) & $(1.850)$ & (0.697) & (0.990) & $(0.632)$ & $(0.082)$ \\
\hline \multirow[t]{2}{*}{0.70} & 0.080 & $-0.252 * *$ & $0.128 * *$ & 0.332 & $0.478 *$ & $0.361 *$ & 0.128 & 0.031 & 0.071 & 0.047 \\
\hline & $(0.002)$ & $(-2.030)$ & $(2.728)$ & $(0.908)$ & (1.959) & (1.864) & $(0.581)$ & $(0.973)$ & $(0.219)$ & $(0.069)$ \\
\hline \multirow[t]{2}{*}{0.80} & 0.101 & $-0.247 * *$ & $0.151 * * *$ & 0.322 & 0.456 & $0.342 *$ & 0.119 & $0.043 *$ & 0.061 & 0.037 \\
\hline & $(0.009)$ & $(-2.012)$ & (3.191) & $(0.889)$ & (1.629) & $(1.741)$ & $(0.621)$ & (1.646) & $(0.129)$ & $(0.078)$ \\
\hline \multirow[t]{2}{*}{0.90} & 0.072 & $-0.239 * *$ & $0.138 * * *$ & 0.317 & 0.472 & $0.355^{*}$ & 0.113 & $0.027 *$ & 0.042 & 0.056 \\
\hline & $(0.030)$ & $(-2.001)$ & (3.001) & $(0.691)$ & (1.610) & (1.699) & $(0.486)$ & (1.705) & $(0.037)$ & $(0.063)$ \\
\hline \multirow[t]{2}{*}{0.95} & 0.100 & $-0.251 * *$ & $0.146^{* * *}$ & 0.321 & 0.460 & $0.362 *$ & 0.109 & $0.013 *$ & 0.077 & 0.048 \\
\hline & $(0.012)$ & $(-2.076)$ & (3.290) & (1.001) & (1.601) & (1.680) & (0.399) & (1.696) & $(0.052)$ & $(0.051)$ \\
\hline
\end{tabular}

Source: Author estimations. Note: The ***,**, * represent level of significance at $1 \%, 5 \%$ and $10 \%$ respectively 
is observed that factors like NRR are causing more carbon emissions in the natural environment of G7 economies.

In addition, the findings in Table 3 also show that FD is significantly and positively linked with carbon emission. However, this linkage is significantly observed only for the lower-order quantiles. This means that more FD is causing more emissions of carbon in the natural environment of the USA. In this regard, research findings, as provided by Shahzad et al. (2017), also confirm the positive impact of FD on carbon emission in the economy of Pakistan. More specifically, it is observed that a $1 \%$ increase in the value of FD will increase carbon emission by $0.165 \%$ under long-run estimation whereas $0.087 \%$ in the short run, respectively. Similarly, Zhang (2011) confirms that FD is an important driver towards the carbon emission in the economy of China. Besides, Khan et al. (2020) have taken a global sample of 192 economies and confirm that FD has an increasing impact on carbon emission.

In addition, the findings under long-run estimation through QARDL also show that urbanization and carbon emission is positively and significantly linked with each other. However, this association is higher for the lower-order quantiles with the coefficient of 0.489 and $t$-score of 2.991, respectively. This means that more urbanization in the USA is leading towards more environmental issues like carbon emission. During and the past decade, a range of studies has confirmed the direct impact of URB in leading towards carbon emission. For example, Zhang et al. (2014) have taken a sample of the Chinese economy during 1978-2011 and found that promoting population urbanization may lead to the growth of carbon intensity. Meanwhile, Wang et al. (2016) consider BRICS economies and confirm a panel causality between urbanization and $\mathrm{CO} 2$ emission, whereas Wang et al. (2015) show that urbanization significantly contributes towards change in the value of per capita carbon emission. Besides, some other studies have confirmed that both urbanization and carbon emission is significantly linked with each other (Prastiyo et al. 2020; Shah et al. 2020; Shi and Li 2018; Sun and Huang 2020; Zhao et al. 2020; Zhou et al. 2021).

The findings in Table 3 also report short-run estimation based on the QARDL approach. It is found that past and lagged values of CO2EM are positively and significantly linked with the current and lagged values of $\mathrm{CO} 2$. More specifically, this relationship is observed as highest for the lower-order quantiles and lower for the medium order quantiles. It means that past carbon emission values are leading towards more emission in the current time and vice versa. Godil et al. (2020) have also found a similar output and confirm that past and lagged values of $\mathrm{CO} 2$ are positively and significantly linked with the current and lagged values of $\mathrm{CO} 2$ in the economy of Pakistan as examined through QARDL estimation. On the other side, the past and lagged values of NRR are positively and significantly linked with the current carbon emission values, but only for the lower-order quantiles of the study. Similarly, for the first three quantiles, past and lagged values of FD are significantly and positively associated with the carbon emission, whereas a similarly significant and positive trend is found for the higher-order quantiles ranging from 0.80th to 0.95 th quantiles, respectively. Besides, URB is found to be positively and significantly linked with the current and lagged values of carbon emission as observed from 0.05 th to 0.30 th.

This research also focuses on the Wald test estimation to examine the parameter linearity reported in Table 4. Considering the findings, the null hypothesis of the speed of adjustment parameter constancy is rejected at a $1 \%$ level of significance. At the same time, the null hypothesis of linearity across various tails of stated quantiles for the long-run parameters is also rejected at a $1 \%$ level of significance. This would justify the argument that the long-run regression coefficients for the study variables like carbon emission, natural resource, FD, and urbanization are dynamic in nature for different quantiles of the study.

Table 4 Results of the Wald test for the constancy of parameters

\begin{tabular}{ll}
\hline Variables & $\begin{array}{l}\text { Wald } \\
\text { statistics [ } p \\
\text { value] }\end{array}$ \\
\hline$P$ & $\begin{array}{l}4.001^{* * *} \\
{[0.000]}\end{array}$ \\
$\beta_{\text {NRR }}$ & $3.043^{* * *}$ \\
& {$[0.000]$} \\
$\beta_{\mathrm{FD}}$ & $6.871^{* * *}$ \\
& {$[0.000]$} \\
$\beta_{\mathrm{URB}}$ & $5.989^{* * *}$ \\
& {$[0.000]$} \\
$\varphi_{1}$ & $8.991^{* * *}$ \\
& {$[0.000]$} \\
$\omega_{0}$ & $2.799^{* *}$ \\
& {$[0.013]$} \\
$\lambda_{0}$ & 0.297 \\
$\theta_{0}$ & {$[0.773]$} \\
& $5.010^{* * *}$ \\
$\theta_{1}$ & {$[0.000]$} \\
& 1.454 \\
Cumulative effect of short run \\
$\theta^{*}$ & 0.161 \\
& {$[0.856]$} \\
\hline
\end{tabular}

Source: Author estimations. Note: The ***,**, * represent level of significance at $1 \%, 5 \%$ and $10 \%$ respectively 
Correspondingly, the findings for the Wald test under short-run estimation also reject the null hypothesis for the cumulative influence of past and lagged values of the carbon emission over study quantiles. Meanwhile, the findings show that explanatory variables like NRR, FD, and urbanization have their nonlinear contemporaneous impact on carbon emission.

Finally, the findings in Table 5 show the $p$ values for the Granger causality in the study quantiles output. Considering the overall study quantiles (i.e., 0.05 th to 0.95 th), the findings confirm a presence of bi-directional causal linkage among the variables of interest in the region of the USA. This would indicate that contemporaneous are the predictors of carbon emission in the USA and vice versa. Furthermore, the findings in Table 5 also confirm that there is a two-way causality between the variables like carbon emission and NRR, carbon emission and FD, and carbon emission and urbanization, respectively. Such output has confirmed the findings through the QARDL test.

\section{Conclusion}

This research tries to investigate the role of FD, NRR, and urbanization in determining the carbon emissions for the USA during 1990-2015 while applying the innovative approach named QARDL as suggested by Cho et al. (2015). The stated method is applied as it checks whether the range of quantiles (lower, medium, and higher) for the NRR, FD, and urbanization is affecting the CO2EM during the study period. This has provided a more detailed explanation for the dependence of carbon emission on the stated variables comparatively to the traditional regression methods like OLS and other techniques. Furthermore, this study has also applied the unit root test to examine the study variables' stationarity properties, whereas the linearity of the study variables is verified with the help of J-B statistics. Finally, causality association between the variables is also verified through the Granger causality method.

The findings through QARDL estimation have confirmed that the error correction parameter is found to be negatively significant for the stated quantiles. This would indicate significant reversion to the long-term association between natural resources, carbon emission, FD, and urbanization in the USA. More specifically, the findings through long-run estimation show that urbanization, FD, and NRR are causing more carbon emissions in the region of the USA during the period of interest. This means that increasing NRR, $\mathrm{FD}$, and urbanization are observed at the cost of more ED, which serious notes need to be addressed. In addition to this, the findings under short-run estimation also confirmed that past and lagged values of carbon emission, FD, urbanization, and NRR are causing a significant change in the current and lagged values of carbon emissions. However, the shortrun estimation is not the same compared to the long-run findings.

\section{Policy implications}

If the empirical output of this study is carefully considered and scrutinized, then a range of policy implications for environmental sustainability can come into existence. For example, as the environmental quality in the form of carbon emission is linked with more urbanization, FD, and NRR, it can be assumed that growth in the US region is not sustainable. Similarly, more FD is putting its adverse pressure on the deterioration of the natural environment. This would
Table 5 Granger causality in quantile test results

\begin{tabular}{lllllll}
\hline Quantiles & $\Delta \mathrm{CO} 2_{t}$ & $\begin{array}{l}\Delta \mathrm{NRR}_{t} \\
\downarrow\end{array}$ & $\begin{array}{l}\Delta \mathrm{CO} 2_{t} \\
\downarrow\end{array}$ & $\begin{array}{l}\Delta \mathrm{FD}_{t} \\
\downarrow\end{array}$ & $\begin{array}{l}\Delta \mathrm{CO} 2_{t} \\
\downarrow\end{array}$ & $\begin{array}{l}\Delta \mathrm{URB}_{t} \\
\downarrow\end{array}$ \\
& $\Delta \mathrm{NRR}_{t}$ & $\Delta \mathrm{CO} 2_{t}$ & $\Delta \mathrm{FD}_{t}$ & $\Delta \mathrm{CO} 2_{t}$ & $\Delta \mathrm{URB}_{t}$ & $\Delta \mathrm{CO} 2_{t}$ \\
\hline$[0.05-0.95]$ & 0.000 & 0.000 & 0.000 & 0.000 & 0.000 & 0.000 \\
0.05 & 0.000 & 0.000 & 0.000 & 0.000 & 0.000 & 0.000 \\
0.10 & 0.000 & 0.000 & 0.000 & 0.000 & 0.000 & 0.000 \\
0.20 & 0.000 & 0.000 & 0.000 & 0.000 & 0.000 & 0.000 \\
0.30 & 0.000 & 0.000 & 0.000 & 0.000 & 0.000 & 0.000 \\
0.40 & 0.000 & 0.000 & 0.000 & 0.000 & 0.000 & 0.000 \\
0.50 & 0.000 & 0.000 & 0.000 & 0.000 & 0.000 & 0.000 \\
0.60 & 0.000 & 0.000 & 0.000 & 0.000 & 0.000 & 0.000 \\
0.70 & 0.000 & 0.000 & 0.000 & 0.000 & 0.000 & 0.000 \\
0.80 & 0.000 & 0.000 & 0.000 & 0.000 & 0.000 & 0.000 \\
0.90 & 0.000 & 0.000 & 0.000 & 0.000 & 0.000 & 0.000 \\
0.95 & 0.000 & 0.000 & 0.000 & 0.000 & 0.000 & 0.000 \\
\hline
\end{tabular}

Source: Author estimation 
indicate that strong policy implications for controlling the harmful effect of FD, urbanization, and NRR are immediately required. This means that the government of the USA should immediately implement those practices which can encourage the green impact of FD and sustainable urbanization in the economy. Additionally, it is suggested that the USA should promote those financial projects and institutions which can significantly work for environment-friendly projects. This may lead to more promotion of some clean energy ventures by financial institutions so that some better output in the form of a sustainable environment would be achieved over a longer period of time. Hence, since the current study elaborates how urbanization, FD, and NRR can cause an increase in carbon emission and environmental degradation, it suggests that the academicians must focus on the impacts of the urbanization, FD, and NRR on carbon emission and environmental degradation and must try to suggest ways to cope with the negative impacts of the urbanization, FD, and NRR on carbon emission and environmental degradation in the further literature. Similarly, this study guides the government, environmental regulators, or country's policymakers to design policies to manage the urbanization, FD, and NRR in such an appropriate manner as they can control their adverse impacts on environmental quality.

Besides, our study is also limited to some macroeconomic dynamics and regional contexts as well. For instance, future studies can consider the dynamic linkage between clean energy sources, ED, trade openness, and various other variables to check the long-run and short-run association between them.

Author contribution Shi-Zheng Huang: conceptualization, writingoriginal draft. Muhammad Sadiq: data curation, writing-literature review and editing. Fengsheng Chien: software, visualization, supervision, methodology.

Funding This article was funded by the China Scholarship Council program (202008440189), Philosophy and Social Science Research in Colleges and Universities in Guangdong Province of China (2019GXJK102), Guangdong Social Science Planning Project (GD20XGL11/GD20XGL20), Natural Science Research Projects of Guangdong University of Petrochemical Technology (2020RC055).

Data availability The data that support the findings of this study are attached.

\section{Declarations}

Ethics approval and consent to participate It can be declared that there are no human participants, human data, or human tissues.

Consent for publication Not applicable.

Competing interests The authors declare no competing interests.

\section{References}

Ali HS, Law SH, Lin WL, Yusop Z, Chin L, Bare UAA (2019) Financial development and carbon dioxide emissions in Nigeria: evidence from the ARDL bounds approach. GeoJournal 84(3):641655. https://doi.org/10.1007/s10708-018-9880-5

Amen R, Hameed J, Albashar G, Kamran HW, Hassan Shah MU, Zaman MKU, ..., Asif S (2021) Modelling the higher heating value of municipal solid waste for assessment of wasteto-energy potential: a sustainable case study. J Clean Prod 287:125575.https://doi.org/10.1016/j.jclepro.2020.125575

An H, Razzaq A, Haseeb M, Mihardjo LW (2021a) The role of technology innovation and people's connectivity in testing environmental Kuznets curve and pollution heaven hypotheses across the Belt and Road host countries: new evidence from method of moments quantile regression. Environ Sci Pollut Res 28(5):5254-5270

An H, Razzaq A, Nawaz A, Noman SM, Khan SAR (2021b) Nexus between green logistic operations and triple bottom line: evidence from infrastructure-led Chinese outward foreign direct investment in Belt and Road host countries. Environ Sci Pollut Res 28:51022-51045. https://doi.org/10.1007/s11356-021-12470-3

Anh Tu C, Chien F, Hussein MA, YantoRamli MM, MochamadSoelton S, Psi MM, Iqbal S, Bilal AR (2021) Estimating role of green financing on energy security, economic and environmental integration of BRI member countries. Singap Econ Rev. https://doi. org/10.1142/S0217590821500193

Aymerich FBJ, Herce JA (2020) Countercyclical labor productivity: the case of Spain. Cuad Econ 43(122):105-118

Bekun FV, Alola AA, Sarkodie SA (2019) Toward a sustainable environment: nexus between $\mathrm{CO} 2$ emissions, resource rent, renewable and nonrenewable energy in 16-EU countries. Sci Total Environ 657:1023-1029. https://doi.org/10.1016/j.scitotenv. 2018.12.104

Canh NP, Kim S, Thanh SD (2020) Entrepreneurship and natural resource rent-seeking: the roles of institutional quality. Econ Bull 40(2):1159-1177

Charfeddine L, Kahia M (2019) Impact of renewable energy consumption and financial development on $\mathrm{CO} 2$ emissions and economic growth in the MENA region: a panel vector autoregressive (PVAR) analysis. Renew Energy 139:198-213. https://doi.org/ 10.1016/j.renene.2019.01.010

Chen Y, He L, Li J, Zhang S (2018) Multi-criteria design of shalegas-water supply chains and production systems towards optimal life cycle economics and greenhouse gas emissions under uncertainty. Comput Chem Eng 109:216-235. https://doi.org/10. 1016/j.compchemeng.2017.11.01

Chien F, Kamran HW, Albashar G, Iqbal W (2021a) Dynamic planning, conversion, and management strategy of different renewable energy sources: a sustainable solution for severe energy crises in emerging economies. Int J Hydrogen Energy 46(11):7745-7758

Chien F, Kamran HW, Nawaz MA, Thach NN, Long PD, Baloch ZA (2021b) Assessing the prioritization of barriers toward green innovation: small and medium enterprises nexus. Environ Dev Sustain:1-31.https://doi.org/10.1007/s10668-021-01513-x

Chien F, Ngo QT, Hsu CC, Chau KY, Iram R (2021c) Assessing the mechanism of barriers towards green finance and public spending in small and medium enterprises from developed countries. Environ Sci Pollut Res. https://doi.org/10.1007/s11356-021-14907-1

Chien F, Pantamee AA, Hussain MS, Chupradit S, Nawaz MA, Mohsin M (2021d) Nexus between financial innovation and bankruptcy: evidence from information, communication and technology (ICT) sector. Singap Econ Rev. https://doi.org/10.1142/S0217 590821500181 
Chien F, Sadiq M, Kamran HW, Nawaz MA, Hussain MS, Raza M (2021e) Co-movement of energy prices and stock market return: environmental wavelet nexus of COVID-19 pandemic from the USA, Europe, and China. Environ Sci Pollut Res:1-15.https:// doi.org/10.1007/s11356-021-12938-2

Chien F, Sadiq M, Nawaz MA, Hussain MS, Tran TD, Le Thanh T (2021f) A step toward reducing air pollution in top Asian economies: the role of green energy, eco-innovation, and environmental taxes. J Environ Manage:297. https://doi.org/10.1016/j.jenvm an.2021.113420

Chien F, Zhang Y, Sadiq M, Hsu CC (2021g) Financing for energy efficiency solutions to mitigate opportunity cost of coal consumption: an empirical analysis of Chinese industries. Environ Sci Pollut Res. https://doi.org/10.1007/s11356-021-15701-9

Cho JS, Kim T-H, Shin Y (2015) Quantile co-integration in the autoregressive distributed-lag modeling framework. J Econ 188(1):281-300

Dong H, Xue M, Xiao Y, Liu Y (2021) Do carbon emissions impact the health of residents? Considering China's industrialization and urbanization. Sci Total Environ 758:143688. https://doi.org/10. 1016/j.scitotenv.2020.143688

Ehsanullah S, Tran QH, Sadiq M, Bashir S, Mohsin M, Iram R (2021) How energy insecurity leads to energy poverty? Do environmental consideration and climate change concerns matters. Environ Sci Pollut Res. https://doi.org/10.1007/s11356-021-14415-2

Godil DI, Sharif A, Agha H, Jermsittiparsert K (2020) The dynamic nonlinear influence of ICT, financial development, and institutional quality on $\mathrm{CO} 2$ emission in Pakistan: new insights from QARDL approach. Environ Sci Pollut Res 27(19):24190-24200

Guo M, Hu Y (2020) The impact of financial development on carbon emission: evidence from China. Sustainability 12(17):6959

Hanif I (2018) Impact of economic growth, nonrenewable and renewable energy consumption, and urbanization on carbon emissions in Sub-Saharan Africa. Environ Sci Pollut Res 25(15):1505715067. https://doi.org/10.1007/s11356-018-1753-4

He L, Chen Y, Li J (2018) A three-level framework for balancing the tradeoffs among the energy, water, and air-emission implications within the life-cycle shale gas supply chains. Resour Conserv Recycl 133:206-228. https://doi.org/10.1016/j.resconrec.2018.02.015

He X, Mishra S, Aman A, Shahbaz M, Razzaq A, Sharif A (2021) The linkage between clean energy stocks and the fluctuations in oil price and financial stress in the US and Europe? Evidence from QARDL approach. Resour Policy 72:102021

Hsu CC, Quang-Thanh N, Chien F, Li L, Mohsin M (2021) Evaluating green innovation and performance of financial development: mediating concerns of environmental regulation. Environ Sci Pollut Res. https://doi.org/10.1007/s11356-021-14499-w

Hu B, Wu Y, Wang H, Tang Y, Wang C (2021) Risk mitigation for rockfall hazards in steeply dipping coal seam: a case study in Xinjiang, northwestern China. Geomat Nat Haz Risk 12(1):9881014. https://doi.org/10.1080/19475705.2021.1909147

Huang SZ, Chau KY, Chien F, Shen H (2020) The impact of startups' dual learning on their green innovation capability: the effects of business executives' environmental awareness and environmental regulations. Sustainability $12(16): 1-17$

Huang Y, Xue L, Khan Z (2021) What abates carbon emissions in China: examining the impact of renewable energy and green investment. Sustain Dev. https://doi.org/10.1002/sd.2177

Huo T, Ma Y, Cai W, Liu B, Mu L (2021) Will the urbanization process influence the peak of carbon emissions in the building sector? A dynamic scenario simulation. Energy Build 232:110590. https:// doi.org/10.1016/j.enbuild.2020.110590

Jiang C, Zhang Y, Kamran HW, Afshan S (2021) Understanding the dynamics of the resource curse and financial development in China? A novel evidence based on QARDL model. Resour Policy 72:102091
Joshua U, Bekun FV (2020a) The path to achieving environmental sustainability in South Africa: the role of coal consumption, economic expansion, pollutant emission, and total natural resources rent. Environ Sci Pollut Res 27(9):9435-9443. https://doi.org/10. 1007/s11356-019-07546-0

Joshua U, Bekun FV (2020b) The path to achieving environmental sustainability in South Africa: the role of coal consumption, economic expansion, pollutant emission, and total natural resources rent. Environ Sci Pollut Res 27(9):9435-9443

Kennedy PL, Schmitz A, DeLong KL (2020) Biotechnology and demand concerns: the case of genetically modified US sugar beets. AgBioforum 22(1):49-60

Khan H, Khan I, Binh TT (2020) The heterogeneity of renewable energy consumption, carbon emission and financial development in the globe: a panel quantile regression approach. Energy Rep 6:859-867. https://doi.org/10.1016/j.egyr.2020.04.002

Koondhar MA, Shahbaz M, Ozturk I, Randhawa AA, Kong R (2021) Revisiting the relationship between carbon emission, renewable energy consumption, forestry, and agricultural financial development for China. Environ Sci Pollut Res. https://doi.org/10.1007/ s11356-021-13606-1

Lahiani A (2018) Revisiting the growth-carbon dioxide emissions nexus in Pakistan. Environ Sci Pollut Res 25(35):35637-35645

Lawrence KOK (2020) Relationship between skills development, employee motivation and organisational performance in South African organisation. Int J Bus Manag Stud 12(1):177-190

Li W, Chien F, Kamran HW, Aldeehani TM, Sadiq M, Nguyen VC, Taghizadeh-Hesary F (2021a) The nexus between COVID-19 fear and stock market volatility. Econ Res Istraživanja. https:// doi.org/10.1080/1331677X.2021.1914125

Li J, Huang X, Chuai X, Yang H (2021b) The impact of land urbanization on carbon dioxide emissions in the Yangtze River Delta, China: a multiscale perspective. Cities 116:103275. https://doi. org/10.1016/j.cities.2021.103275

Li W, Chien F, Hsu C-C, Zhang Y, Nawaz MA, Iqbal S, Mohsin M (2021c) Nexus between energy poverty and energy efficiency: estimating the long-run dynamics. Resour Policy 72:1-9. https:// doi.org/10.1016/j.resourpol.2021.102063

Li Z-Z, Li RYM, Malik MY, Murshed M, Khan Z, Umar M (2021d) Determinants of carbon emission in China: how good is green investment? Sustain Prod Consumption 27:392-401

Li X, Li Z, Jia T, Yan P, Wang D, ..., Liu G (2021e) The sense of community revisited in Hankow, China: combining the impacts of perceptual factors and built environment attributes. Cities 111:103108.https://doi.org/10.1016/j.cities.2021.103108

Li J, Zhao Y, Zhang A, Song B, Hill RL (2021f) Effect of grazing exclusion on nitrous oxide emissions during freeze-thaw cycles in a typical steppe of Inner Mongolia. Agric Ecosyst Environ 307.https://doi.org/10.1016/j.agee.2020.107217

Lin B, Raza MY (2020) Analysis of energy security indicators and $\mathrm{CO} 2$ emissions. A case from a developing economy. Energy 200:117-136. https://doi.org/10.1016/j.techfore. 2019.119862

Liu Z, Tang YM, Chau KY, Chien F, Iqbal W, Sadiq M (2021) Incorporating strategic petroleum reserve and welfare losses: a way forward for the policy development of crude oil resources in South Asia. Resour Policy. https://doi.org/10.1016/j.resourpol. 2021.102309

Lv Z, Li S (2021) How financial development affects CO2 emissions: a spatial econometric analysis. J Environ Manage 277:111129. https://doi.org/10.1016/j.jenvman.2020.111397

Mahmood H, Alkhateeb TTY, Furqan M (2020) Industrialization, urbanization and $\mathrm{CO} 2$ emissions in Saudi Arabia: asymmetry analysis. Energy Rep 6:1553-1560. https://doi.org/10.1016/j. egyr.2020.06.004 
Mensi W, Shahzad SJH, Hammoudeh S, Hkiri B, Al Yahyaee KH (2019) Long-run relationships between US financial credit markets and risk factors: evidence from the quantile ARDL approach. Finance Res Lett 29:101-110

Mignamissi D, Djeufack A (2021) Urbanization and CO2 emissions intensity in Africa. J Environ Plan Manage 8:1-25. https://doi. org/10.1080/09640568.2021.1943329

Mohsin M, Kamran HW, Nawaz MA, Hussain MS, Dahri AS (2021) Assessing the impact of transition from nonrenewable to renewable energy consumption on economic growth-environmental nexus from developing Asian economies. J Environ Manage 284:111999

Musah M, Kong Y, Mensah IA, Antwi SK, Donkor M (2021) The connection between urbanization and carbon emissions: a panel evidence from West Africa. Environ Dev Sustain 23(8):1152511552. https://doi.org/10.1007/s10668-020-01124-y

Nawaz MA, Hussain MS, Kamran HW, Ehsanullah S, Maheen R, Shair F (2021a) Trilemma association of energy consumption, carbon emission, and economic growth of BRICS and OECD regions: quantile regression estimation. Environ Sci Pollut Res 28(13):16014-16028

Nawaz MA, Seshadri U, Kumar P, Aqdas R, Patwary AK, Riaz M (2021b) Nexus between green finance and climate change mitigation in N-11 and BRICS countries: empirical estimation through difference in differences (DID) approach. Environ Sci Pollut Res 28(6):6504-6519. https://doi.org/10.1007/ s11356-020-10920-y

Ncube B, Koloba HA (2020) Branded mobile app usage intentions among generation $Y$ students: a comparison of gender and education level. Int. J eBus. eGovernment Stud 12(2):91-106. https:// doi.org/10.34111/ijebeg.202012201

Odugbesan JA, Adebayo TS (2020) The symmetrical and asymmetrical effects of foreign direct investment and financial development on carbon emission: evidence from Nigeria. SN Appl Sci 2(12):1982. https://doi.org/10.1007/s42452-020-03817-5

Odugbesan JA, Rjoub H (2020) Relationship among economic growth, energy consumption, $\mathrm{CO} 2$ emission, and urbanization: evidence from MINT countries. SAGE Open 10(2):2158244020914648. https://doi.org/10.1177/2158244020914648

Othman Z, Nordin MFF, Sadiq M (2020) GST fraud prevention to ensure business sustainability: a Malaysian case study. J Asian Bus Econ Stud 27(3):245-265

Ozturk I, Acaravci A (2013) The long-run and causal analysis of energy, growth, openness and financial development on carbon emissions in Turkey. Energy Econ 36:262-267

Prastiyo SE, Hardyastuti S (2020) How agriculture, manufacture, and urbanization induced carbon emission? The case of Indonesia. Environ Sci Pollut Res 27(33):42092-42103

Prastiyo SE, Irham, Hardyastuti S, Jamhari (2020) How agriculture, manufacture, and urbanization induced carbon emission? The case of Indonesia. Environ Sci Pollut Res 27(33):42092-42103. https://doi.org/10.1007/s11356-020-10148-w

Razzaq A, Sharif A, Aziz N, Irfan M, Jermsittiparsert K (2020) Asymmetric link between environmental pollution and COVID-19 in the top ten affected states of US: a novel estimations from quantile-on-quantile approach. Environ Res 191:110189

Razzaq A, Sharif A, Najmi A, Tseng ML, Lim MK (2021) Dynamic and causality interrelationships from municipal solid waste recycling to economic growth, carbon emissions and energy efficiency using a novel bootstrapping autoregressive distributed lag. Resour Conserv Recycl 166:105372

Razzaq A, Sharif A, Ahmad P, Jermsittiparsert K (2021b) Asymmetric role of tourism development and technology innovation on carbon dioxide emission reduction in the Chinese economy: fresh insights from QARDL approach. Sustain Dev 29(1):176-193
Razzaq A, Wang Y, Chupradit S, Suksatan W, Shahzad F (2021) Asymmetric inter-linkages between green technology innovation and consumption-based carbon emissions in BRICS countries using quantile-on-quantile framework. Technol Soc 66:101656

Razzaq A, Ajaz T, Li JC, Irfan M, Suksatan W (2021) Investigating the asymmetric linkages between infrastructure development, green innovation, and consumption-based material footprint: novel empirical estimations from highly resource-consuming economies. Resour Policy 74:102302

Sadiq M, Hsu CC, Zhang Y, Chien FS (2021a) COVID-19 fear and volatility index movements: empirical insights from ASEAN stock markets. Environ Sci Pollut Res. https://doi.org/10.1007/ s11356-021-15064-1

Sadiq M, Nonthapot S, Mohamad, Keong OC, Ehsanullah S, Iqbal N (2021b) Does green finance matters for sustainable entrepreneurship and environmental corporate social responsibility during COVID-19? China Finance Rev Int. https://doi.org/10.1108/ CFRI-02-2021-0038

Shah SAR, Naqvi SAA, Anwar S (2020) Exploring the linkage among energy intensity, carbon emission and urbanization in Pakistan: fresh evidence from ecological modernization and environment transition theories. Environ Sci Pollut Res 27(32):40907-40929. https://doi.org/10.1007/s11356-020-09227-9

Shahbaz M, Lahiani A, Abosedra S, Hammoudeh S (2018) The role of globalization in energy consumption: a quantile cointegrating regression approach. Energy Econ 71:161-170

Shahzad SJH, Kumar RR, Zakaria M, Hurr M (2017) Carbon emission, energy consumption, trade openness and financial development in Pakistan: a revisit. Renew Sustain Energy Rev 70:185-192. https://doi.org/10.1016/j.rser.2016.11.042

Shair F, Shaorong S, Kamran HW, Hussain MS, Nawaz MA (2021) Assessing the efficiency and total factor productivity growth of the banking industry: do environmental concerns matters? Environ Sci Pollut Res 28(16):20822-20838

Shan S, Genç SY, Kamran HW, Dinca G (2021) Role of green technology innovation and renewable energy in carbon neutrality: a sustainable investigation from Turkey. J Environ Manag 294:113004

Shi X, Li X (2018) Research on three-stage dynamic relationship between carbon emission and urbanization rate in different city groups. Ecol Ind 91:195-202. https://doi.org/10.1016/j.ecolind. 2018.03.056

Sun W, Huang C (2020) How does urbanization affect carbon emission efficiency? Evidence from China. J Clean Prod 272:122828. https://doi.org/10.1016/j.jclepro.2020.122828

Sun H, Awan RU, Nawaz MA, Mohsin M, Rasheed AK, Iqbal N (2020) Assessing the socio-economic viability of solar commercialization and electrification in south Asian countries. Environ Dev Sustain:1-23. https://doi.org/10.1007/s10668-020-01038-9

Tsunga KR, Moores-Pitt P, Mccullough K (2020) A non-linear analysis of South African exports and selected macroeconomic variables. Int J Econ Financ 12(2):436-452. https://doi.org/10.34109/ijefs. 202012212

Tufail M, Song L, Adebayo TS, Kirikkaleli D, Khan S (2021) Do fiscal decentralization and natural resources rent curb carbon emissions? Evidence from developed countries. Environ Sci Pollut Res. https://doi.org/10.1007/s11356-021-13865-y

Ullah A, Ahmed M, Raza SA, Ali S (2021a) A threshold approach to sustainable development: nonlinear relationship between renewable energy consumption, natural resource rent, and ecological footprint. J Environ Manage 295:113073. https://doi.org/10. 1016/j.jenvman.2021.113073

Ullah A, Ahmed M, Raza SA, Ali S (2021b) A threshold approach to sustainable development: nonlinear relationship between renewable energy consumption, natural resource rent, and ecological footprint. J Environ Manage 295:113-129. https://doi.org/10. 1016/j.jenvman.2021.113073 
Ulucak R, Ozcan B (2020) Relationship between energy consumption and environmental sustainability in OECD countries: the role of natural resources rents. Resourc Policy 69:101803

Umar M, Ji X, Kirikkaleli D, Xu Q (2020) COP21 Roadmap: do innovation, financial development, and transportation infrastructure matter for environmental sustainability in China? J Environ Manage 271:111026. https://doi.org/10.1016/j.jenvman.2020.111026

Umar M, Ji X, Kirikkaleli D, Alola AA (2021a) The imperativeness of environmental quality in the United States transportation sector amidst biomass-fossil energy consumption and growth. J Clean Prod 285:124863. https://doi.org/10.1016/j.jclepro.2020.124863

Umar M, Ji X, Mirza N, Naqvi B (2021b) Carbon neutrality, bank lending, and credit risk: evidence from the Eurozone. J Environ Manage 296:113156. https://doi.org/10.1016/j.jenvman.2021.113156

Wang Q, Wang L (2021) The nonlinear effects of population aging, industrial structure, and urbanization on carbon emissions: a panel threshold regression analysis of 137 countries. J Clean Prod 287:125381. https://doi.org/10.1016/j.jclepro.2020. 125381

Wang Y, Zhang X, Kubota J, Zhu X, Lu G (2015) A semi-parametric panel data analysis on the urbanization-carbon emissions nexus for OECD countries. Renew Sustain Energy Rev 48:704-709. https://doi.org/10.1016/j.rser.2015.04.046

Wang Y, Li L, Kubota J, Han R, Zhu X, Lu G (2016) Does urbanization lead to more carbon emission? Evidence from a panel of BRICS countries. Appl Energy 168:375-380. https://doi.org/10.1016/j. apenergy.2016.01.105

Wang L, Vo XV, Shahbaz M, Ak A (2020) Globalization and carbon emissions: is there any role of agriculture value-added, financial development, and natural resource rent in the aftermath of COP21? J Environ Manage 268:110712. https://doi.org/10. 1016/j.jenvman.2020.110712

Wang W-Z, Liu L-C, Liao H, Wei Y-M (2021a) Impacts of urbanization on carbon emissions: an empirical analysis from OECD countries. Energy Policy 151:112171. https://doi.org/10.1016/j. enpol.2021.112171

Wang F, Lu Y, Li J, Ni J (2021b) Evaluating environmentally sustainable development based on the PSR framework and variable weigh analytic hierarchy process. Int J Environ Res Public Health 18(6):2836. https://doi.org/10.3390/ijerph18062836

Wu B, Fang H, Jacoby G, Li G, Wu Z (2021) Environmental regulations and innovation for sustainability? Moderating effect of political connections. Emerg Mark Rev 100835.https://doi.org/ 10.1016/j.ememar.2021.100835

Xueying W, Sadiq M, Chien F, Ngo Q-T, Nguyen A-T, Trinh T-T (2021) Testing role of green financing on climate change mitigation: evidences from G7 and E7 countries. Environ Sci Pollut Res. https://doi.org/10.1007/s11356-021-15023-w
Zaidi SAH, Zafar MW, Shahbaz M, Hou F (2019) Dynamic linkages between globalization, financial development and carbon emissions: evidence from Asia Pacific Economic Cooperation countries. J Clean Prod 228:533-543. https://doi.org/10.1016/j.jclep ro.2019.04.210

Zhang Y-J (2011) The impact of financial development on carbon emissions: an empirical analysis in China. Energy Policy 39(4):21972203. https://doi.org/10.1016/j.enpol.2011.02.026

Zhang Y-J, Liu Z, Zhang H, Tan T-D (2014) The impact of economic growth, industrial structure and urbanization on carbon emission intensity in China. Nat Hazards 73(2):579-595

Zhang G, Zhang N, Liao W (2018) How do population and land urbanization affect $\mathrm{CO} 2$ emissions under gravity center change? A spatial econometric analysis. J Clean Prod 202:510-523. https://doi. org/10.1016/j.jclepro.2018.08.146

Zhang W, Cui Y, Wang J, Wang C, Streets DG (2020) How does urbanization affect $\mathrm{CO} 2$ emissions of central heating systems in China? An assessment of natural gas transition policy based on nighttime light data. J Clean Prod 276:123-142. https://doi.org/10.1016/j. jclepro.2020.123188

Zhao Z, Yuan T, Shi X, Zhao L (2020) Heterogeneity in the relationship between carbon emission performance and urbanization: evidence from China. Mitig Adapt Strat Glob Change 25(7):1363-1380. https://doi.org/10.1007/s11027-020-09924-3

Zhao F, Song L, Peng Z, Yang J, Luan G, Chu C, ..., Xie Z (2021a) Night-time light remote sensing mapping: construction and analysis of ethnic minority development index. Remote Sens (Basel) 13(11):2129.https://doi.org/10.3390/rs13112129

Zhao F, Zhang S, Du Q, Ding J, Luan G, ..., Xie Z (2021b) Assessment of the sustainable development of rural minority settlements based on multidimensional data and geographical detector method: a case study in Dehong, China. Socio-Econ Plan Sci. https://doi.org/10.1016/j.seps.2021.101066

Zhou C, Wang S, Wang J (2019) Examining the influences of urbanization on carbon dioxide emissions in the Yangtze River Delta, China: Kuznets curve relationship. Sci Total Environ 675:472482. https://doi.org/10.1016/j.scitotenv.2019.04.269

Zhou Y, Chen M, Tang Z, Mei Z (2021) Urbanization, land use change, and carbon emissions: quantitative assessments for city-level carbon emissions in Beijing-Tianjin-Hebei region. Sustain Cities Soc 66:102701. https://doi.org/10.1016/j.scs.2020.102701

Zhuang Y, Yang S, Chupradit S, Nawaz MA, Xiong R, Koksal C (2021) A nexus between macroeconomic dynamics and trade openness: moderating role of institutional quality. Bus Process Manag J. https://doi.org/10.1108/BPMJ-12-2020-0594

Publisher's note Springer Nature remains neutral with regard to jurisdictional claims in published maps and institutional affiliations. 